CMEARTICLE

\title{
Clinics in diagnostic imaging (206)
}

Emma Choon Hwee Lee ${ }^{1}$, BSc, MBBS, Prasanna Sivanath Tirukonda ${ }^{1}$, MBBS, FRCR, Andrew Gee Seng $\underline{T a n}^{1}$, MBBS, FRCR, Haiyuan $\underline{\text { Shi }}{ }^{1}$, MBBS, FRCR
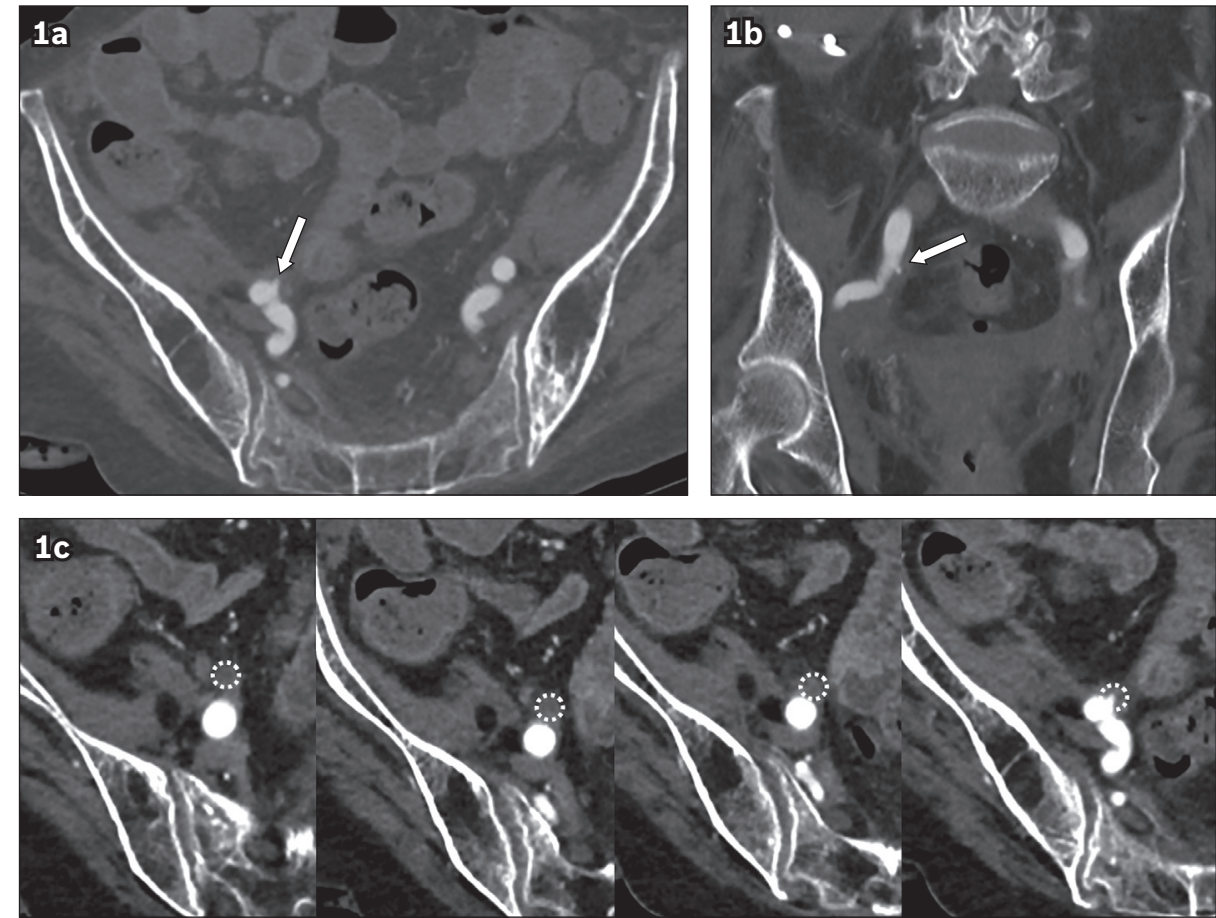

Fig. 1 Contrast-enhanced CT angiogram of the lower abdomen in (a) axial, (b) coronal and (c) magnified consecutive axial view.

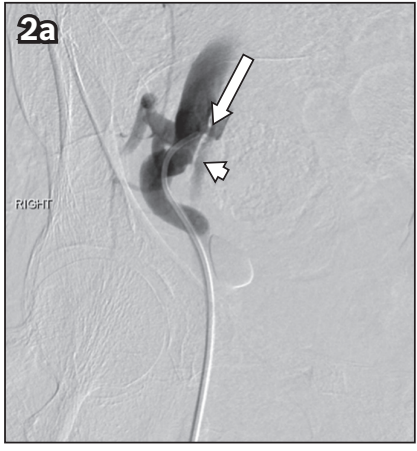

Fig. 2 Digital subtraction angiograms of the right common iliac artery.

\section{CASE PRESENTATION}

A 69-year-old woman with a history of cervical carcinoma underwent a total hysterectomy, bilateral salpingo-oophorectomy and pelvic lymph node dissection followed by chemoradiotherapy. She developed radiotherapy-related ureteral strictures requiring long-term ureteric stents.

Three years after the implantation of the ureteric stents, she presented with recurrent gross haematuria. Extensive investigations with serial computed tomography (CT) studies, flexible cystoscopy, ureteroscopy and retrograde pyelogram

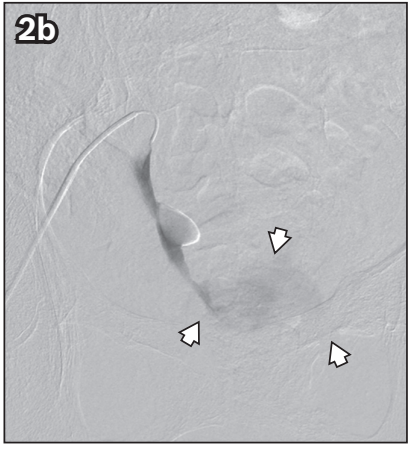

failed to reveal a cause and she was diagnosed with radiation cystitis. Her existing ureteric stents, which were thought to be exacerbating factors, were removed and bilateral nephrostomies were placed.

She subsequently suffered an episode of massive haematuria and hypotension with blood pressure of $70 / 50 \mathrm{mmHg}$. Laboratory tests revealed a drop in haemoglobin level from $10 \mathrm{~g} / \mathrm{dL}$ to $6 \mathrm{~g} / \mathrm{dL}$. CT angiography of the abdomen and pelvis (Fig. 1) and urgent catheter angiography (Fig. 2) were performed. What do the images show? What is the diagnosis? 


\section{IMAGE INTERPRETATION}

Arterial phase axial and coronal CT images show a tiny outpouching arising from the right common iliac artery (arrow, Fig. 1a \& b). Magnified consecutive axial CT images (Fig. 1c) show the course of the right common iliac artery in relation to the right ureter (dotted circles), which can be traced from its origin at the right pelvicalyceal system (not shown in this image). A tiny medially orientated outpouching arising from the wall of the right common iliac artery is seen at its intersection with the ureter, in keeping with a pseudoaneurysm abutting the adjacent right ureter (Fig. 1c).

Digital subtraction angiography (DSA; Fig. 2a) shows a 5-French (Fr) Cobra C2 catheter within the right common iliac artery. There is opacification of a fistulous communication (arrow) between the right common iliac artery and an adjacent tubular structure (arrowhead). A microcatheter was passed through the Cobra catheter to access this tubular structure. Injection of contrast through the microcatheter led to opacification of the urinary bladder (arrowheads in Fig. 2b), confirming the tubular structure to be the right ureter.

\section{DIAGNOSIS}

Arterioureteral fistula (AUF).

\section{CLINICAL COURSE}

The diagnosis of AUF was ultimately only made during catheter angiography, which was performed with a view to carrying out arterial embolisation. Initial selective angiography of both renal arteries and the left internal iliac artery did not reveal a source of haemorrhage.

The right common iliac artery was accessed with a 5-Fr Cobra C2 catheter. A non-selective angiographic run performed in an attempt to cannulate the right internal iliac artery resulted in opacification of the right ureter, diagnostic of an AUF (Fig. 2). Balloon tamponade of the haemorrhage into the right ureter was performed with a $7 \mathrm{~mm} \times 40 \mathrm{~mm}$ balloon catheter (REEF HP, Invatec, Medtronic, Roncadelle, Italy) before insertion of an $8 \mathrm{~mm}$ $\times 100 \mathrm{~mm}$ Gore ${ }^{\circledR}$ Viabahn ${ }^{\circledR}$ stent-graft (WL Gore \& Associates, Flagstaff, AZ, USA) into the right common iliac artery across the fistulous communication (Fig. 3). Post-stent insertion dilatation was performed with a partially inflated $10 \mathrm{~mm} \times 80 \mathrm{~mm}$ balloon catheter (DORADO ${ }^{\circledR}$, Bard Peripheral Vascular Inc, Tempe, AZ, USA) to mould the stent against the vascular wall. A final check on angiography showed no further extravasation of contrast into the right ureter.

The patient remained well post intervention with no further episodes of haematuria to date.

\section{DISCUSSION}

AUF is a rare cause of haematuria resulting from fistulous communication between the ureter and the aorta or iliac artery. Primary AUFs (15\%) arise from arterial pathologies such as aortoiliac aneurysms or arteriovenous malformations that erode into the ureter. ${ }^{(1,2)}$ Secondary AUFs (85\%) are more common and result from malignancy, surgery, radiotherapy or ureteric
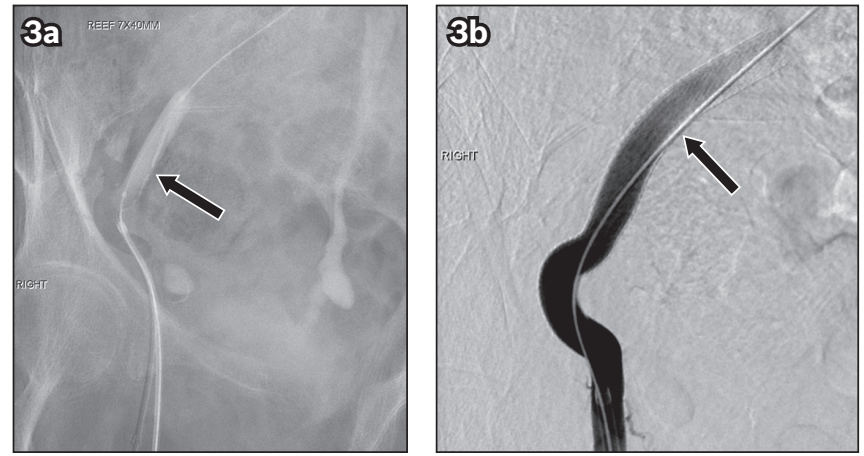

Fig. 3 (a) Angiogram shows balloon tamponade of the haemorrhage into the right ureter using a $7 \mathrm{~mm} \times 40 \mathrm{~mm}$ balloon catheter (arrow) and (b) an $8 \mathrm{~mm} \times 100 \mathrm{~mm}$ Gore ${ }^{\circledR}$ Viabahn ${ }^{\circledR}$ stent-graft (arrow) placed across the arterioureteral fistula, occluding it with no further contrast flow into the right ureter.

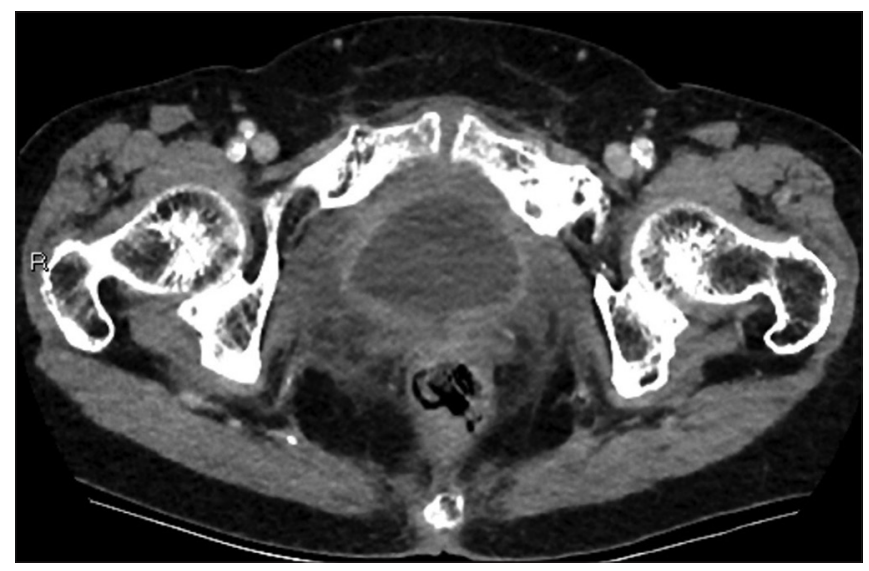

Fig. 4 An 80-year-old woman with a history of cervical cancer treated with radiotherapy presented 20 years later with gross haematuria. Axial contrastenhanced CT image shows circumferential thickening and irregularity of the bladder wall with surrounding fat stranding compatible with radiation cystitis.

stents, which trigger chronic inflammation and fibrosis, leading to adhesion and eventual fistulation of the fragile ureter and adjacent pulsatile artery. ${ }^{(3,4)}$ This was the likely process in our patient, who had a history of gynaecological malignancy treated with surgery, radiotherapy and ureteric stents, all of which are well-known risk factors for developing secondary AUF. While AUF is an uncommon condition, its incidence is increasing as ageing populations undergo aggressive cancer treatment. To date, at least 139 cases have been reported in the literature. ${ }^{(2,5)}$

Patients with AUF present with haematuria, which may or may not be associated with flank pain. ${ }^{(2)}$ The degree of haematuria can range from intermittent haematuria to life-threatening massive haematuria with a mortality rate of $13 \% .^{(2,5)}$ Due to its non-specific presentation, more common causes of gross haematuria such as radiation cystitis (Fig. 4), cyclophosphamide-induced cystitis and bladder malignancy (Fig. 5) are often considered first and may coexist with AUFs, confounding the diagnosis. ${ }^{(6,7)}$ In a review of 139 cases of AUF, the diagnosis had not been considered in most of the patients who died from the condition. ${ }^{(5)}$ Therefore, awareness of this disease entity is important to ensure prompt diagnosis and treatment.

Cystoscopic evaluation may reveal pulsatile bleeding from the ureteral orifice alluding to an AUF, but this may be absent at the 


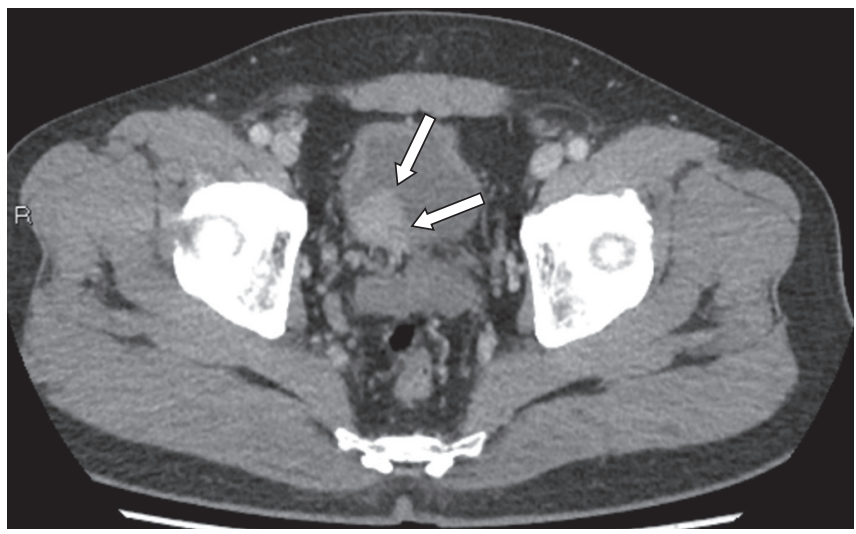

Fig. 5 A 50-year-old man presented with gross haematuria. Axial contrast enhanced CT image shows an enhancing soft tissue lesion (arrows) at the right vesicoureteric junction. Cystoscopy confirmed a solid mass at this location and histology revealed papillary urothelial carcinoma.

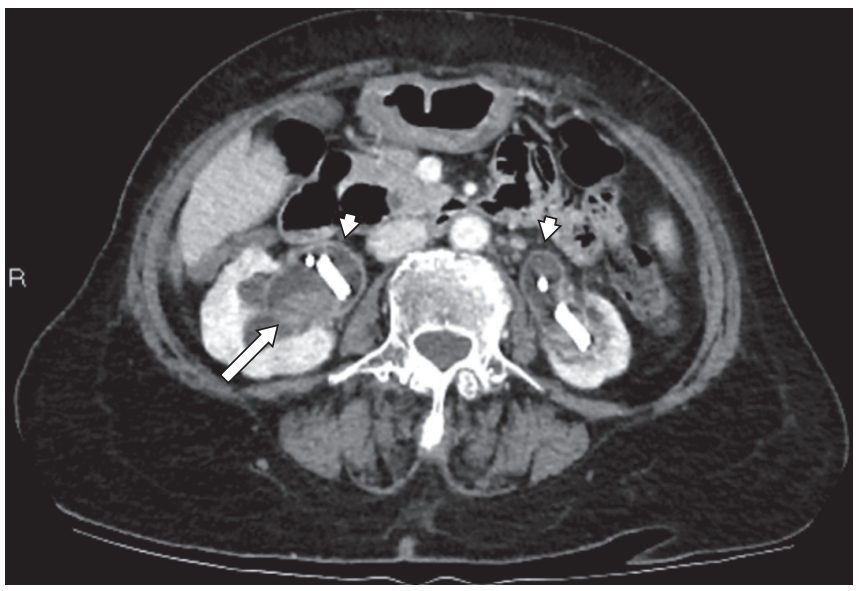

Fig. 6 A 69-year-old woman who developed radiotherapy-related ureteral strictures requiring long-term ureteric stents underwent CT imaging for recurrent haematuria while the ureteric stents were in situ. Axial contrastenhanced CT image shows non-specific findings of bilateral hydronephrosis (arrowheads) with hyperdense blood products (arrow) within the right pelvicalyceal system.

time of examination. ${ }^{(2)} \mathrm{CT}$ is reported to be only moderately useful and often yields non-specific findings such as hydronephrosis and blood clots within the urinary system, also demonstrated in this case (Fig. 6). ${ }^{(4,5,8)}$ However, CT may prove invaluable when interpreted with a high degree of clinical suspicion. One imaging finding associated with AUF is the appearance of a pseudoaneurysm, which is noted to be present in up to $38 \%$ of cases. ${ }^{(5)}$ The pseudoaneurysm in this case was extremely subtle and may be easily missed if AUF is not suspected (Fig. 1).

AUFs occur at the region of the ureteric crossing; in the native ureter, this is usually at the distal common iliac artery with less common sites being the external or internal iliac arteries. ${ }^{(2)}$ In patients with urinary diversion, the proximal common iliac artery or distal abdominal aorta may be involved instead. ${ }^{(2)}$ Massive haematuria in a patient with risk factors should prompt a targeted review of these areas using CT for the presence of a pseudoaneurysm.
Direct fistulous communication between the artery and ureter is difficult to demonstrate without DSA, which remains the gold standard in the imaging diagnosis of AUF with a reported sensitivity of $69 \% .^{(2,5)}$ Findings on DSA may range from subtle arterial wall irregularity or pseudoaneurysm to active extravasation of contrast into the ureter. ${ }^{(2)}$ To optimise the diagnostic yield of CT and DSA, ureteric stents should be removed to allow visualisation of contrast flow into the ureter. Unfortunately, false negative angiography studies are possible and provocative manoeuvres may be required. One previously described technique is the use of a balloon catheter to sweep across the ureter at the suspected point of fistulation while an arteriogram is obtained from an ipsilateral arterial access to demonstrate contrast extravasation into the ureter. ${ }^{(9)}$

Previously, AUFs were treated by surgical repair of the involved artery and ureter, which is particularly difficult in patients who have adhesions from surgery and radiotherapy. Currently, the most commonly performed procedure is endovascular treatment with balloon tamponade of the haemorrhage before placement of a stent graft across the fistula, while other techniques such as coil embolisation of the affected artery are less common. ${ }^{(2)}$

The literature on the long-term outcome of endovascular treatment in patients with AUF is currently sparse. A small study of 14 cases reported complications such as lower limb ischaemia, deep vein thrombosis, skin ulceration, chronic leg pain, femoral head osteonecrosis, limb amputation and recurrent haemorrhage. ${ }^{(10)}$

In conclusion, AUF is a relatively rare cause of haematuria, but its incidence is increasing as more pelvic cancers are detected and treated aggressively. CT findings may be non-specific, and a high index of suspicion is required when interpreting studies of patients with risk factors. DSA remains the gold standard for imaging diagnosis and allows for concomitant endovascular management, which is now favoured over surgical repair.

\section{REFERENCES}

1. Takahashi $Y$, Hirai H, Sasaki $Y$, et al. Successful surgical treatment for rupture of an iliac artery aneurysm into a ureter. Ann Vasc Dis 2009; 2:58-61.

2. Pillai AK, Anderson ME, Reddick MA, Sutphin PD, Kalva SP. Ureteroarterial fistula: diagnosis and management. AJR Am J Roentgenol 2015; 204:W592-8.

3. Bergqvist D, Pärsson H, Sherif A. Arterio-ureteral fistula--a systemic review. Eur J Vasc Endovasc Surg 2001; 22:191-6.

4. Madoff DC, Gupta S, Toombs BD, et al. Arterioureteral fistulas: a clinical, diagnostic, and therapeutic dilemma. AJR Am J Roentgenol 2004; 182:1241-50.

5. van den Bergh RC, Moll FL, de Vries JP, Lock TM. Arterioureteral fistulas: unusual suspects--systematic review of 139 cases. Urology 2009; 74:251-5.

6. Liguori G, Amodeo A, Mucelli FP, et al. Intractable haematuria: long-term results after selective embolization of the internal iliac arteries. BJU Int 2010; 106:500-3.

7. Arrizabalaga M, Extramiana J, Parra JL, et al. Treatment of massive haematuria with aluminous salts. Br J Urol 1987; 60:223-6.

8. Muraoka N, Sakai T, Kimura H, et al. Endovascular treatment for an iliac arteryureteral fistula with a covered stent. J Vasc Interv Radiol 2006; 17:1681-5.

9. Quillin SP, Darcy MD, Picus D. Angiographic evaluation and therapy of ureteroarterial fistulas. AJR Am J Roentgenol 1994; 162:873-8.

10. Fox JA, Krambeck A, McPhail EF, Lightner D. Ureteroarterial fistula treatment with open surgery versus endovascular management: long-term outcomes. J Urol 2011; 185:945-50. 


\section{SINGAPORE MEDICAL COUNCIL CATEGORY 3B CME PROGRAMME} (Code SMJ 202006B)

Question 1. Regarding arterioureteral fistulas:

(a) Primary arterioureteral fistulas are more common than secondary arterioureteral fistulas.

(b) Primary arterioureteral fistulas are usually a result of chronic inflammation and fibrosis from previous surgery or radiotherapy.

(c) They commonly occur at the ureteric crossing involving the distal common iliac artery.

(d) Their incidence is decreasing due to improvements in surgical and radiotherapy techniques.

Question 2. Regarding the clinical presentation of arterioureteral fistulas:

(a) The degree of gross haematuria is variable.

(b) The condition has a low mortality rate of $<1 \%$.

(c) Patients often have risk factors such as malignancy, previous pelvic surgery and radiotherapy.

(d) Co-existing pathologies such as radiation or chemotherapy-related cystitis may confound the diagnosis.

Question 3. The following is the gold standard for the diagnosis of arterioureteral fistula:
(a) Cystoscopy.
(b) Digital subtraction angiography.
(c) CT urogram.
(d) CT angiography.

Question 4. Regarding diagnosis of arterioureteral fistulas:

(a) CT has high sensitivity and specificity in the diagnosis of arterioureteral fistulas.

(b) CT findings include hydronephrosis and blood clots within the urinary system.

(c) An iliac artery pseudoaneurysm is a common CT finding seen in most cases.

(d) Digital subtraction angiography is reported to be $69 \%$ sensitive in the detection of arterioureteral fistula.

Question 5. Regarding management of arterioureteral fistulas:

(a) Any existing ureteric stents should be left in situ to avoid exacerbating the patient's haematuria.

(b) Surgical repair of the involved artery and ureter is now the most commonly performed procedure for the management of arterioureteral fistulas.

(c) Insertion of a stent graft across the arterioureteral fistula is more commonly performed than embolisation of the affected artery.

(d) Reported complications of endovascular treatment include lower limb ischaemia, deep vein thrombosis and limb amputation.

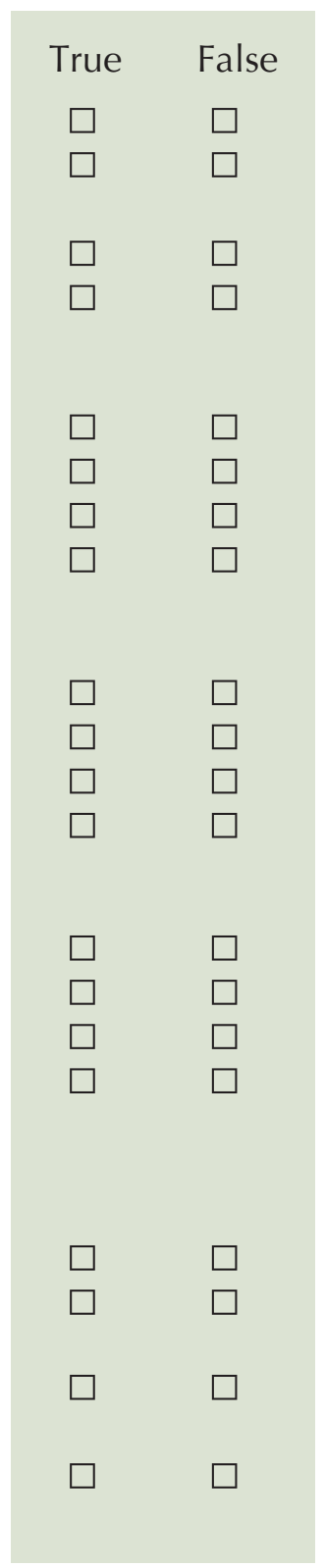

\section{Doctor's particulars:}

Name in full:

MCR no.:

Specialty:

Email:

\section{SUBMISSION INSTRUCTIONS}

Visit the SMJ website: http://www.smj.org.sg/current-issue and select the appropriate quiz. You will be redirected to the SMA login page.

For SMA member: (1) Log in with your username and password (if you do not know your password, please click on 'Forgot your password?'). (2) Select your answers for each quiz and click 'Submit'.

For non-SMA member: (1) Create an SMJ CME account, or log in with your SMJ CME username and password (for returning users). (2) Make payment of SGD 21.40 (inclusive of $7 \%$ GST) via PayPal to access this month's quizzes. (3) Select your answers for each quiz and click 'Submit'.

RESULTS:

(1) Answers will be published online in the SMJ August 2020 issue. (2) The MCR numbers of successful candidates will be posted online at the SMJ website by 10 August 2020. (3) Passing mark is $60 \%$. No mark will be deducted for incorrect answers. (4) The SMJ editorial office will submit the list of successful candidates to the Singapore Medical Council. (5) One CME point is awarded for successful candidates. (6) SMC credits CME points according to the month of publication of the CME article (i.e. points awarded for a quiz published in the June 2020 issue will be credited for the month of June 2020, even if the deadline is in August 2020).

Deadline for submission (June 2020 SMJ 3B CME programme): 12 noon, 3 August 2020. 